\title{
Analgesic Efficacy of Etoricoxib following Third Molar Surgery: A Meta-analysis
}

\author{
Lorenzo Franco-de la Torre $\left(\mathbb{D},{ }^{1}\right.$ Diana Laura Franco-González $\mathbb{D}^{1},{ }^{1}$ \\ Lorena Michele Brennan-Bourdon $\mathbb{D}^{2},{ }^{2}$ Nelly Molina-Frechero $\mathbb{( D}{ }^{3}$ \\ Ángel Josabad Alonso-Castro $\mathbb{1}^{4},{ }^{4}$ and Mario Alberto Isiordia-Espinoza $\mathbb{\circledR}^{1}$ \\ ${ }^{1}$ Instituto de Investigación en Ciencias Médicas, Cuerpo Académico Terapéutica y Biología Molecular (UDG-CA-973), \\ Departamento de Clínicas, División de Ciencias Biomédicas, Centro Universitario de los Altos, Universidad de Guadalajara, \\ Tepatitlán de Morelos, Jalisco, Mexico \\ ${ }^{2}$ Comisión para la Protección Contra Riesgos Sanitarios del Estado de Jalisco, Guadalajara, Jalisco, Mexico \\ ${ }^{3}$ Departamento de Salud, Laboratorio de Cariología y Medicina Oral, Universidad Autónoma Metropolitana-Xochimilco, \\ Ciudad de México, Mexico \\ ${ }^{4}$ Departamento de Farmacia, División de Ciencias Naturales y Exactas, Universidad de Guanajuato, Guanajuato, Mexico
}

Correspondence should be addressed to Mario Alberto Isiordia-Espinoza; mario.isiordia162@yahoo.com

Received 28 May 2021; Accepted 31 July 2021; Published 9 September 2021

Academic Editor: Muh-Shi Lin

Copyright (c) 2021 Lorenzo Franco-de la Torre et al. This is an open access article distributed under the Creative Commons Attribution License, which permits unrestricted use, distribution, and reproduction in any medium, provided the original work is properly cited.

\begin{abstract}
Background. The purpose of this meta-analysis was to assess the clinical efficacy of etoricoxib in comparison with traditional NSAIDs for postoperative pain after third molar surgery. Methods. The quality of studies found in PubMed and Google Scholar was evaluated with Cochrane Collaboration's risk of bias tool. Data on total consumption of rescue analgesics, number of patients using rescue analgesics, global assessment of study treatments, and adverse effects were extracted exclusively from highquality clinical trials. Each meta-analysis was performed with the Review Manager Software 5.3 for Windows. Results. The qualitative analysis showed that etoricoxib has better analgesic activity when compared with ibuprofen ( 2 clinical trials) and diclofenac (1 clinical trial). A similar analgesic efficacy between etoricoxib and nonselective Cox-2 NSAIDs was informed in $3 / 8$ studies ( 2 compared to ibuprofen and 1 to naproxen sodium). Moreover, the number of patients requiring rescue analgesics in the postoperative period showed a statistical difference in favor of etoricoxib when compared to NSAIDs. Conclusion. Etoricoxib significantly reduces the number of patients needing rescue analgesics compared to NSAIDs after third molar surgery.
\end{abstract}

\section{Introduction}

Surgical removal of a mandibular third molar is an important clinical tool to evaluate the analgesic efficacy of new drugs $[1,2]$. Surgical injuries on the soft tissue, and particularly trauma on the mandibular bone, produce moderate to severe pain which starts after the anesthetic activity and lasts for several days [1-6].

The most common available drugs to treat dental pain after third molar removal are nonsteroidal anti-inflammatory analgesic drugs (NSAIDs) [7, 8]. The selective enzyme cyclooxygenase-2 (COX-2) inhibitor NSAIDs have similar clinical efficacy as nonselective (COX-2) NSAIDs for the management of osteoarthritis [9] and postsurgical dental pain [10]. Moreover, this type of drug has been related to severe adverse effects, such as myocardial infarction [11-13], acute kidney injury [14], hepatotoxicity [15], and hypersensitivity [16].

Etoricoxib, a relatively new selective (COX-2) NSAIDs, has been used in several clinical studies to control postoperative complications following a third mandibular molar extraction [17-24], and it has shown similar clinical efficacy than nonselective NSAIDs [20, 21, 24].

Recently, a meta-analysis by González-Barnadas et al. [10] showed the clinical efficacy and safety of COX-2 
inhibitors versus ibuprofen for relief of postoperative pain after third molar surgery. However, the clinically important analgesic effect of etoricoxib alone following third molar surgery was not evaluated. In addition, that meta-analysis included a small number of clinical trials to assess the effectiveness and tolerability of etoricoxib compared with ibuprofen in oral surgery [10]. Therefore, the purpose of this systematic review and meta-analysis was to evaluate the analgesic effectiveness of etoricoxib versus other NSAIDs in dental science reports.

\section{Materials and Methods}

2.1. Literature Search in PubMed and Google Scholar. Both PubMed and Google Scholar were utilized to search for clinical studies using the following keywords: "etoricoxib," "ibuprofen," "naproxen," "diclofenac," "ketorolac," "nonsteroidal anti-inflammatory drugs," "oral surgery," "dental surgery," and "third molar surgery." Article types and language filters ("English" and "Spanish") were used in PubMed. All clinical trials comparing the clinical effectiveness of etoricoxib and nonselective NSAIDs published up to July 2020 were eligible. This activity was performed by two independent researchers.

2.2. Population, Interventions, Control, and Outcome (PICO) Strategy. Population: patients undergoing third molar removal.

Interventions: etoricoxib administration.

Control: cyclooxygenase 2 nonselective NSAIDs.

Outcomes: total rescue analgesic consumption, number of patients using rescue analgesics, pain intensity using the Visual Analog Scale (VAS), and global assessment of treatment [25].

The articles that met the specifications of the PICO strategy were turned over for evaluation with Cochrane Collaboration's risk of bias tool.

2.3. Risk of Bias Assessment. Quality assessment of each clinical assay was performed with Cochrane Collaboration's risk of bias tool [25-29]. Two independent researchers conducted the full evaluation of each report, and their differences were discussed to obtain a consensus [27-29]. The studies without a high risk of bias were deliberated as high quality (low risk of bias).

2.4. Data Extraction. The extracted data were as follows: author, design study, treatment groups, size sample $(n)$, dose, total rescue analgesic consumption, number of patients using rescue analgesics, and global evaluation of treatment.

When an article presented two groups of etoricoxib (90 and $120 \mathrm{mg}$ ), the events and sample size of the control group were included in the statistical analysis by half to not unrealistically increase the sample size of the combined analysis (i.e., the cases of Brown et al. [19] and Daniels et al. [21]). To do this, the same study reference was used with an added key that allowed the inclusion of the review article by the aforementioned authors on two occasions in the same meta-analysis (Brown et al. [19] and Brown et al. [19-2]; and Daniels et al. [21] and Daniels et al. [21-2]).
2.5. Statistical Analysis. The inverse variance statistical method with the standardized mean difference was used to assess the numerical data. Mantel-Haenszel test and odds ratio (OR) were utilized to analyze the dichotomous data. The pooled analysis and forest plot were executed with the Review Manager Software 5.3 for Windows. A $p$ value test $\leq 0.05$, mean difference, or OR ( $>1$ and within $95 \%$ confidence intervals (CIs)) were considered statistically significant [26, 30-32].

\section{Results}

3.1. Digital Search. Through both databases, 149 scientific articles were identified. This revision did not include clinical trials using etoricoxib in endodontics or periodontics, as well as those studies comparing etoricoxib with an active control other than NSAIDs [33-37]. After excluding duplicate reports and considering the focus of this review, 11 papers fulfilled the PICO strategy (Figure 1).

3.2. Risk of Bias Assessment. A total of 8 reports met the quality criteria according to Cochrane Collaboration's risk of bias tool and were used in the qualitative analysis [17-24]. In the quantitative analysis, only 6 articles were included [19-24]. According to Cochrane Collaboration's risk of bias tool, the double-blinded nature was the main problem of the excluded articles [38-40] (Figure 2).

3.3. Qualitative Analysis. In line with the quality studies, etoricoxib was compared with ibuprofen in 6 papers, 1 study with diclofenac, and 1 clinical assay versus naproxen sodium. The etoricoxib dose of $120 \mathrm{mg}$ was used in all quality studies in this review (dose range of etoricoxib: 60 to $240 \mathrm{mg}$ ). Most studies used a single-dose etoricoxib and a postoperative analgesia approach (Table S1).

According to the conclusions by the authors of each study, the qualitative analysis showed that etoricoxib has better analgesic activity when compared with ibuprofen (2 clinical trials) and diclofenac (1 clinical trial) [19, 22, 24]. A similar analgesic efficacy between etoricoxib and nonselective Cox-2 NSAIDs was informed in 3/8 studies (2 compared to ibuprofen and 1 to naproxen sodium) $[20,21,23]$ (Table S1).

3.4. Quantitative Analysis: Analgesic Efficacy. Total rescue analgesic consumption was informed only by Calvo et al. [20] (mean difference $=-0.44 ; 95 \% \mathrm{ICs}=-1.38$ to $0.5 ; p=$ $0.36)$. The number of patients who needed rescue analgesic medication was reported in 5 trials [19-21, 23, 24]. A reduction in the number of patients requiring rescue analgesics was observed in patients who took etoricoxib when compared to NSAIDs ( $p=0.0004$; Figure 3$)$. In this sense, the number of patients needing rescue analgesic medication was lower for etoricoxib in comparison with ibuprofen $400 \mathrm{mg}$ [24] ( $p=0.00001$; Figure 4).

The global evaluation of the study treatments showed a trend in favor of etoricoxib without a statistical difference (Figures 5 and 6). 


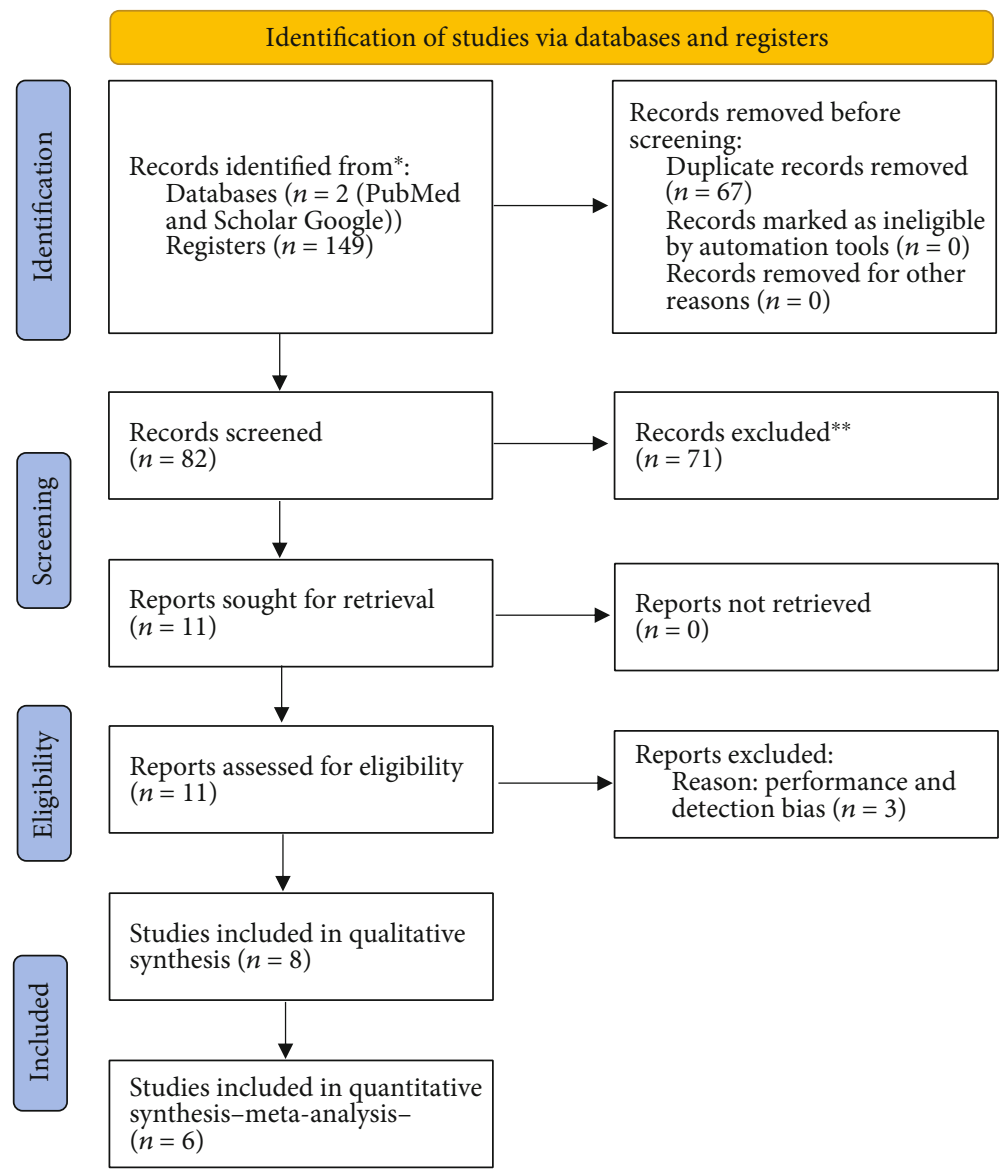

FIgURE 1: Study flow diagram.

3.5. Adverse Effects. The overall adverse effect evaluation of etoricoxib and nonselective (COX-2) NSAIDs was performed using 6 clinical trials [19-24]. The analysis showed no statistical difference (Figure 7).

\section{Discussion}

This is the first meta-analysis to evaluate the individual analgesic effectiveness of etoricoxib in comparison with nonselective (COX-2) NSAIDs following third molar surgery. The most important finding of this review was the lower number of patients who required rescue analgesia in the etoricoxib group when compared with the NSAID group. It should be noted that most indicators of analgesic efficacy were measured dichotomously. For this reason, we could assume that this efficacy evaluation is appropriate [41].

Recently, a meta-analysis by González-Barnadas et al. [10] carried out the pooled analysis of total pain relief (TOPAR), rescue analgesic consumption, and adverse reactions of COX-2 inhibitors versus ibuprofen after third molar removal [10]. In that report, the qualitative analysis included only 3 articles $[17,21,24]$ and the meta-analysis just 2 articles $[21,24]$ because Albuquerque et al. [17] did not provide data for quantitative analysis [10]. The authors concluded that coxibs (also known as COX-2 inhibitors) have an analgesic effect similar to ibuprofen when used in third molar surgery [10]. In other words, the effect of selective COX-2 inhibitors was evaluated globally, and thus, the efficacy of individual coxibs was not known. In our meta-analysis, the assessment of the analgesic effectiveness showed a smaller number of patients requiring rescue analgesics in favor of etoricoxib when compared to NSAIDs after third molar surgery.

The clinical efficacy of etoricoxib in relieving postoperative pain could be explained by the potency with which this agent inhibits the COX-2 enzyme. In vitro tests with whole human blood have described the COX-2 selectivity ratio- $\left(\mathrm{IC}_{50}=\mathrm{COX}-1 / \mathrm{COX}-2\right)$ - of etoricoxib and other NSAIDs as follows: etoricoxib $=106$, valdecoxib $=30$, celecoxib $=7.6$, nimesulide $=7.3$, ibuprofen $=0.2$, diclofenac $=3$, meloxicam $=2$, piroxicam $=0.08$, and indomethacin $=$ 0.4 [42]. Furthermore, animal studies confirm a superior analgesic potency of etoricoxib compared to other coxibs or NSAIDs. In this sense, we could consider the effective dose $50\left(\mathrm{ED}_{50}\right)$ as a measure of drug's potency [43]. Thus, the $\mathrm{ED}_{50}$ of etoricoxib was $3.27 \mathrm{mg} / \mathrm{kg}$ [44], parecoxib $=1.6 \mathrm{mg} /$ $\mathrm{kg}$ [45], celecoxib $=11.58 \mathrm{mg} / \mathrm{kg}$ [44], meloxicam $=6.5 \mathrm{mg}$ / $\mathrm{kg}$ [45], nimesulide $=7.6 \mathrm{mg} / \mathrm{kg}$ [45], piroxicam $=8.5 \mathrm{mg} / \mathrm{kg}$ [45], ibuprofen $=58.13 \pm 5.32 \mathrm{mg} / \mathrm{kg}$ [44], diclofenac $=8.1$ $\mathrm{mg} / \mathrm{kg}$ [45], metamizol $=28.5 \mathrm{mg} / \mathrm{kg}$ [45], naproxen $=46.4$ $\mathrm{mg} / \mathrm{kg}$ [45], ketoprofen $=30.3 \mathrm{mg} / \mathrm{kg}$ [45], and paracetamol $=225.36 \pm 1.02 \mathrm{mg} / \mathrm{kg}$ [44] when administered intraperitoneally in the acetic acid-induced abdominal contortions in mice $[44,45]$. 

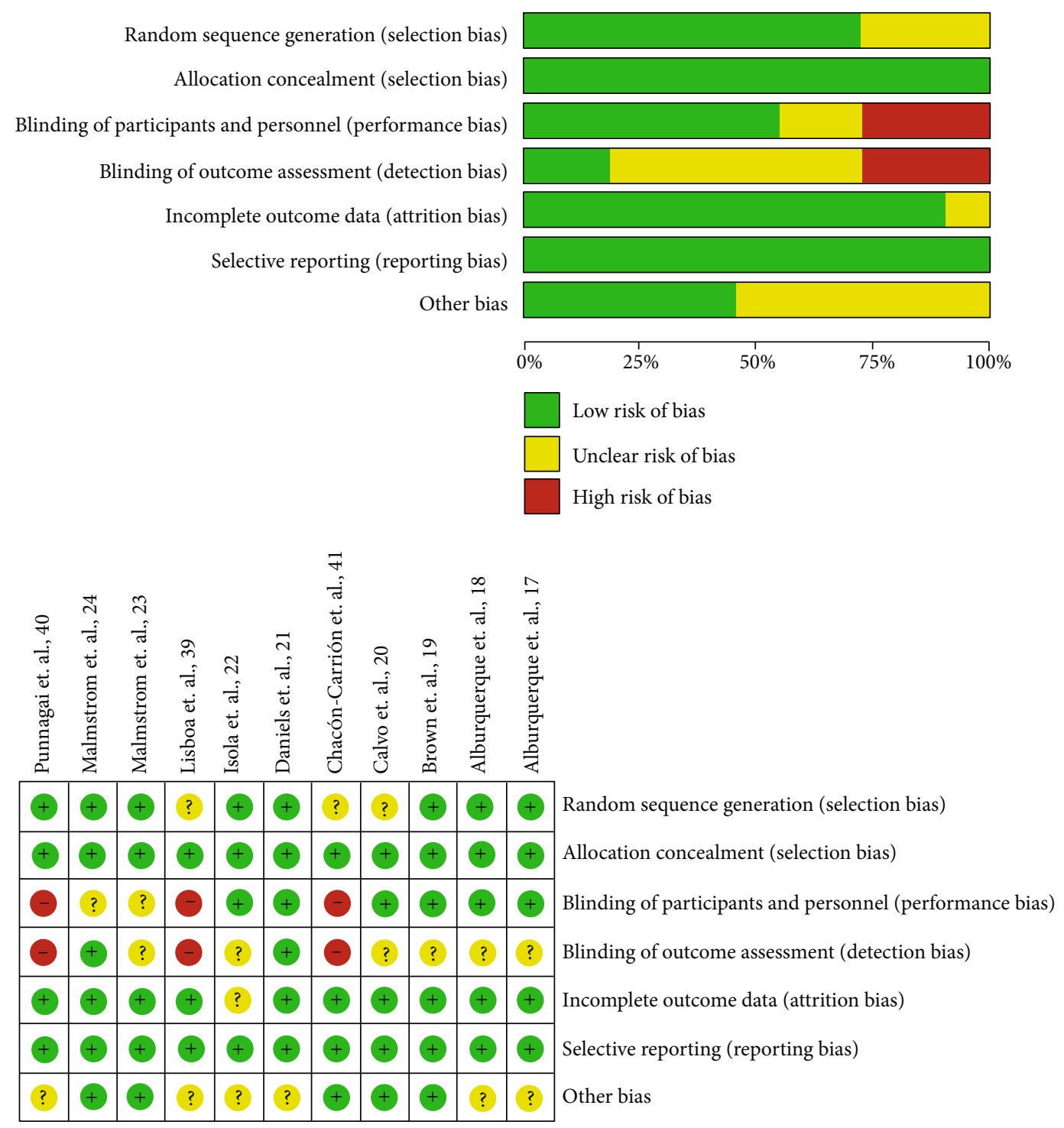

FIgURE 2: Risk of bias assessment of full text articles.

The assessment of adverse effects by González-Barnadas et al. [10] showed that ibuprofen produced an increased risk of nausea and vomiting compared to COX-2 selective drugs, recommending the use of these latter drugs in patients with a clinical history of gastrointestinal upset. Other systematic reviews and meta-analyses have compared etoricoxib with placebo [46-49]. Aldington et al. [46] found limited clinical evidence of increased cardiovascular risk in patients who took etoricoxib versus placebo. Moreover, the pooled evaluations of adverse reactions from Clarke et al. [47-49] showed a similar risk between etoricoxib and placebo. Baraf et al. [50] assessed the risk of adverse effects of etoricoxib and diclofenac, and the findings showed that etoricoxib had better gastrointestinal tolerability when compared to diclofenac in patients with osteoarthritis. In addition, de Vecchis et al. [51] evaluated 17 clinical trials to analyze the cardiovascular risk of etoricoxib, and the authors concluded that there is no evidence indicating that etoricoxib increases the risk of serious cardiovascular adverse effects when com- pared to placebo. Zhang et al. [52] assessed different renal events (peripheral edema, hypertension, and renal dysfunction) in 15 clinical trials employing etoricoxib. The authors demonstrated that etoricoxib did not produce any renal alterations. In our meta-analysis, evaluation of minor adverse effects (e.g., nausea, vomiting, dizziness, and headache) showed no statistical differences between etoricoxib and ibuprofen.

The adherence to the PRISMA guidelines, the use of high-quality clinical trials to perform the statistical analysis, and a large sample size are some of the main advantages of our report. On the other hand, the main obstacle of this review and meta-analysis was its retrospective design [53-56].

In conclusion, the number of patients requiring rescue analgesics was lower for etoricoxib when compared to NSAIDs after third molar surgery. Furthermore, according to data extracted from clinical trials with low risk of bias, the safety profiles of etoricoxib and NSAIDs were similar. 


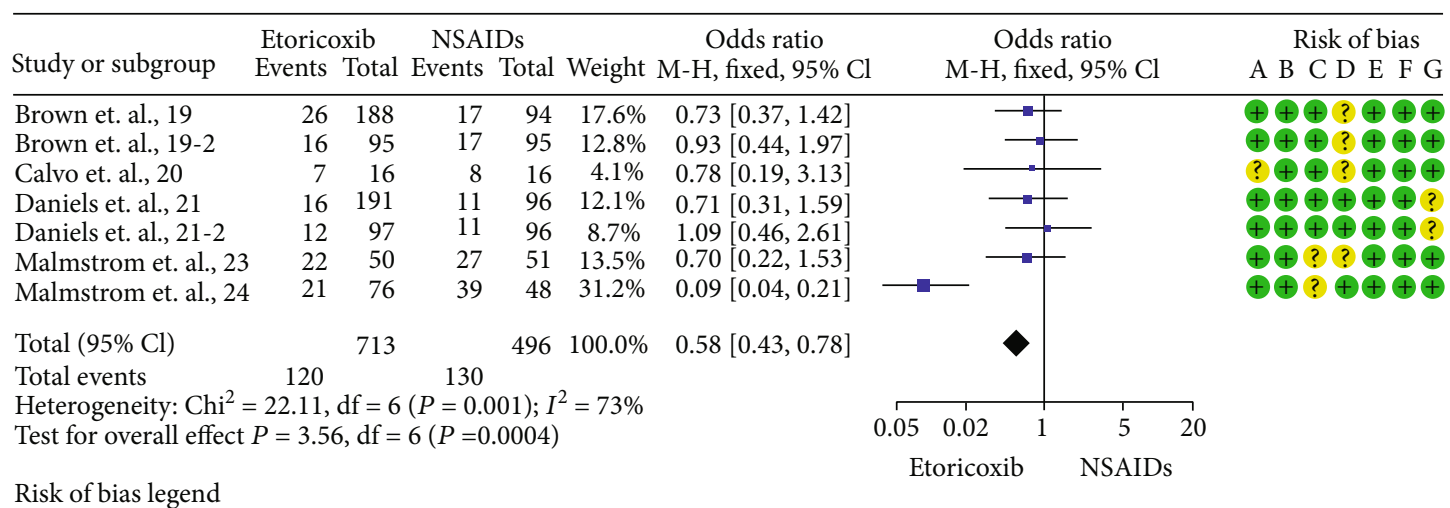

(A) random sequence generation (selection bias)

(B) allocation concealment (selection bias)

(C) blinding of participants and personnel (performance bias)

(D) blinding of outcome assessment (detection bias)

(E) incomplete outcome data (attrition bias)

(F) selective reporting (reporting bias)

(G) other bias

FIGURE 3: Overall evaluation of the number of patients requiring rescue analgesia.

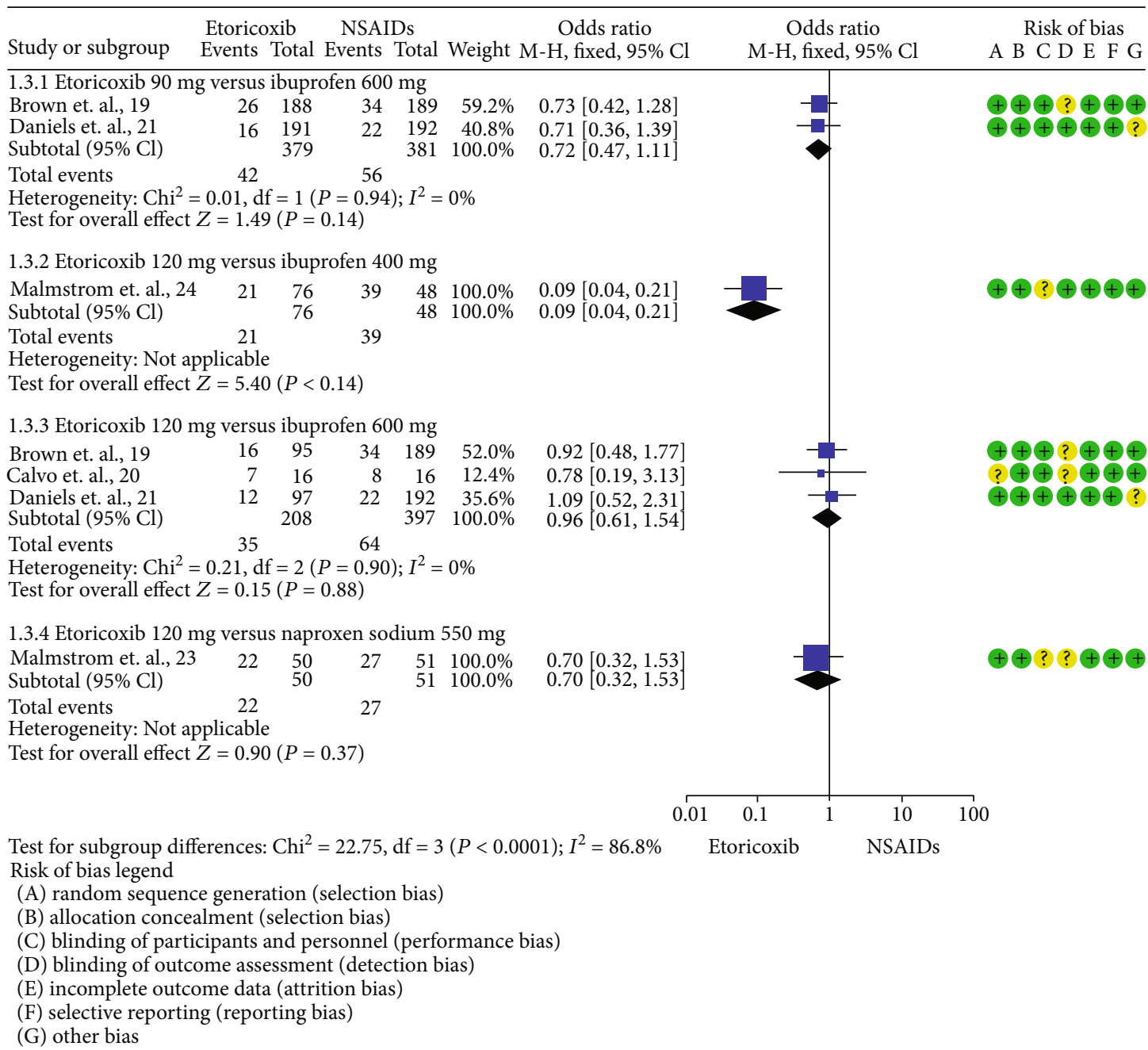

Figure 4: Pooled evaluation according to the etoricoxib dose and the number of patients needing rescue analgesic medication. 


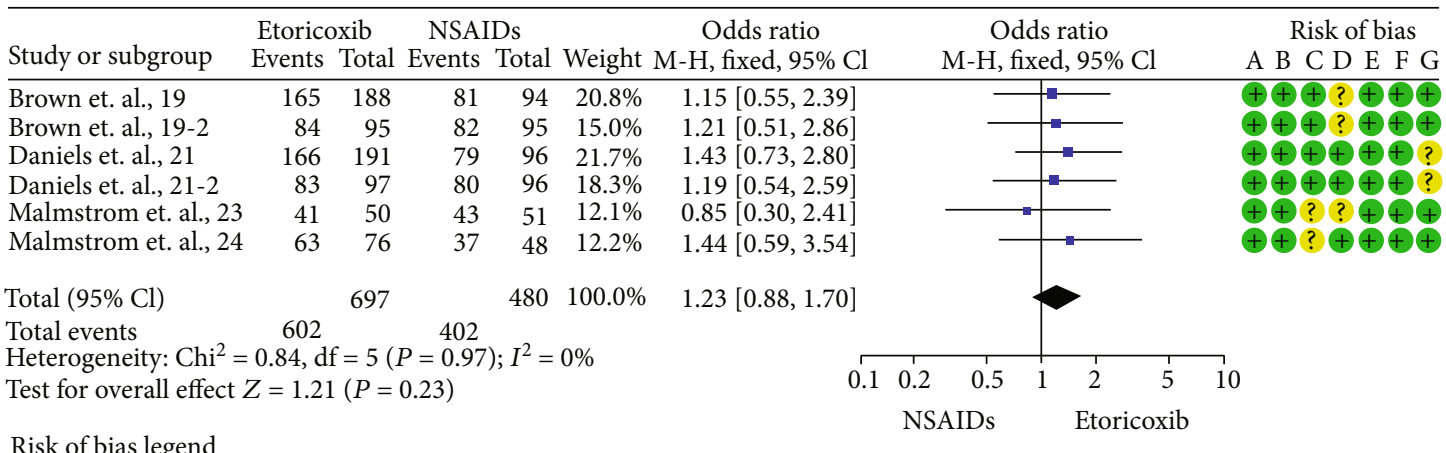

Risk of bias legend

(A) random sequence generation (selection bias)

(B) allocation concealment (selection bias)

(C) blinding of participants and personnel (performance bias)

(D) blinding of outcome assessment (detection bias)

(E) incomplete outcome data (attrition bias)

(F) selective reporting (reporting bias)

(G) other bias

FIgURE 5: Global assessment of the study medication.

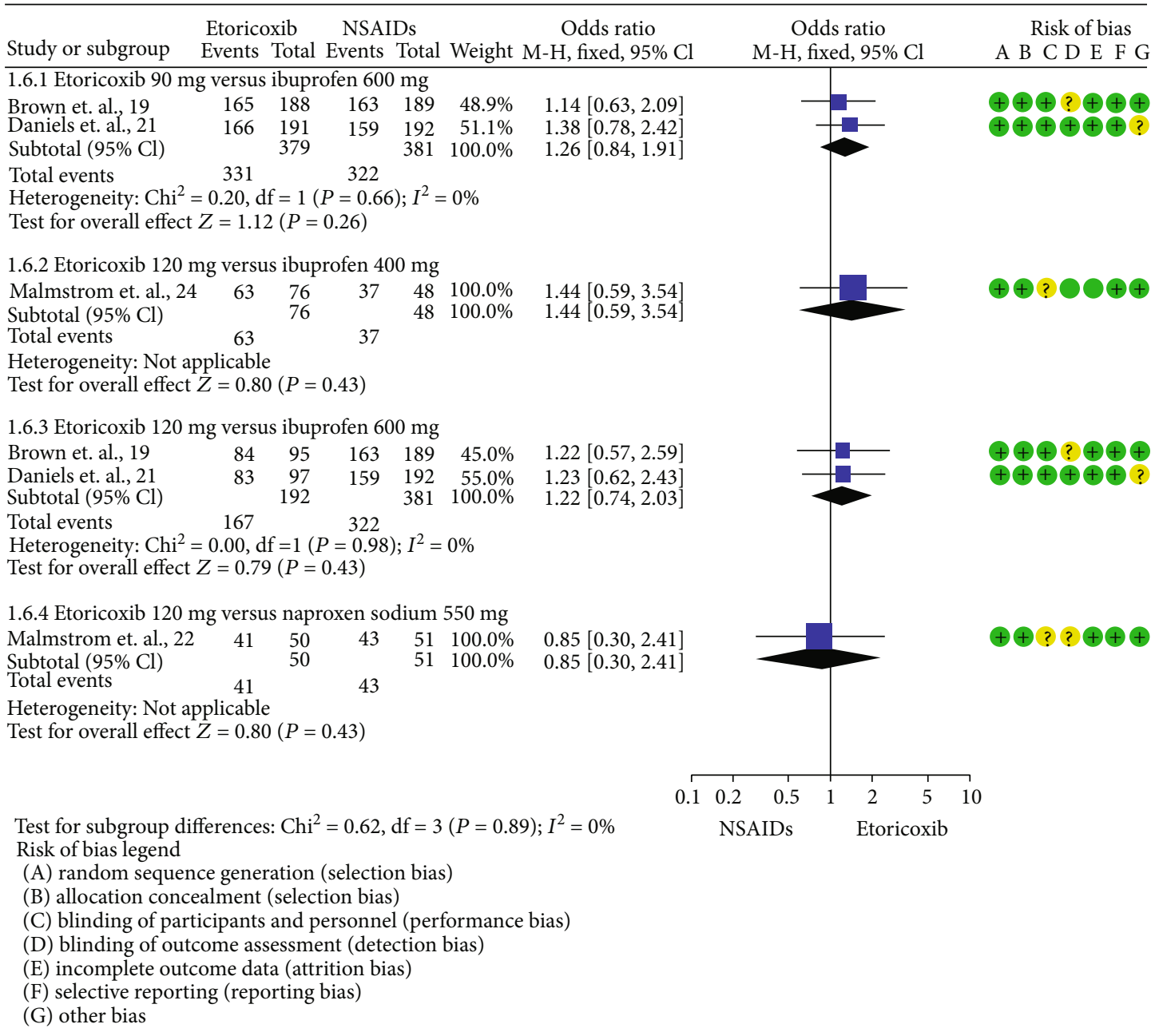

FIgURE 6: Meta-analysis according to the etoricoxib dose and patient satisfaction. 


\begin{tabular}{|c|c|c|c|c|c|c|}
\hline \multirow[b]{2}{*}{ Study or subgroup } & \multicolumn{2}{|c|}{ Etoricoxib } & \multicolumn{2}{|c|}{ NSAIDs } & & \multirow{2}{*}{$\begin{array}{c}\text { Odds ratio } \\
\mathrm{M}-\mathrm{H} \text {, fixed, } 95 \% \mathrm{Cl}\end{array}$} \\
\hline & & Total & Events & Total & Weight & \\
\hline \multicolumn{7}{|l|}{ 2.1.1 Nausea } \\
\hline Brown et. al., 2013 & 3 & 283 & 4 & 189 & $20.6 \%$ & $0.50[0.11,2.24]$ \\
\hline Calvo et. al., 2006 & 0 & 16 & 0 & 16 & & Not estimable \\
\hline Daniels et. al., 2011 & 10 & 288 & 10 & 192 & $50.2 \%$ & $0.65[0.27,1.60]$ \\
\hline Isola et. al., 2019 & 0 & 32 & 0 & 32 & & Not estimable \\
\hline Malmstrom et. al., 2004a & 4 & 50 & 2 & 51 & $7.9 \%$ & $2.13[0.37,12.19]$ \\
\hline Malmstrom et. al., $2004 \mathrm{~b}$ & 15 & 301 & 3 & 48 & $21.3 \%$ & $0.79[0.22,2.83]$ \\
\hline Subtotal $(95 \% \mathrm{Cl})$ & & 970 & & 528 & $100.0 \%$ & $0.77[0.42,1.41]$ \\
\hline \multirow{2}{*}{\multicolumn{7}{|c|}{ Heterogeneity: $\mathrm{Chi}^{2}=1.76, \mathrm{df}=3(P=0.62) ; I^{2}=0 \%$}} \\
\hline & & & & & & \\
\hline \multicolumn{7}{|c|}{ Test for overall effect $Z=0.86(P=0.39)$} \\
\hline \multicolumn{7}{|l|}{ 2.1.2 Nausea } \\
\hline Brown et. al., 2013 & 0 & 283 & 1 & 189 & $20.0 \%$ & $0.22[0.01,5.47]$ \\
\hline Calvo et. al., 2006 & 0 & 16 & 0 & 16 & & Not estimable \\
\hline Daniels et. al., 2011 & 3 & 288 & 2 & 192 & $26.4 \%$ & $1.00[0.17,6.04]$ \\
\hline Isola et. al., 2019 & 0 & 32 & 0 & 32 & & Not estimable \\
\hline Malmstrom et. al., 2004a & 0 & 50 & 1 & 51 & $16.4 \%$ & $0.33[0.01,8.38]$ \\
\hline Malmstrom et. al., $2004 \mathrm{~b}$ & 9 & 301 & 2 & 48 & $37.2 \%$ & $0.71[0.15,3.39]$ \\
\hline Subtotal $(95 \% \mathrm{Cl})$ & & 970 & & 528 & $100.0 \%$ & $0.63[0.23,1.72]$ \\
\hline Total events & 12 & & 6 & & & \\
\hline
\end{tabular}

Heterogeneity: $\mathrm{Chi}^{2}=0.83, \mathrm{df}=3(P=0.84) ; I^{2}=0 \%$

Test for overall effect $Z=0.91(P=0.36)$

\subsubsection{Dizziness}

Brown et. al., 2013

Calvo et. al., 2006

Daniels et. al., 2011

Isola et. al., 2019

Malmstrom et. al., 2004a

Malmstrom et. al., 2004b

Subtotal $(95 \% \mathrm{Cl})$

Total events

$\begin{array}{rr}1 & 283 \\ 0 & 16 \\ 4 & 288 \\ 0 & 32 \\ 1 & 50 \\ 12 & 301 \\ & 970\end{array}$

18

$2 \quad 18929.6 \% \quad 0.33[0.03,3.68]$

$3 \quad 192 \quad 44.0 \% \quad 0.89[0.20,4.01]$

$\begin{array}{lll}0 & 32 & \text { Not estimable }\end{array}$

$\begin{array}{llll}0 & 51 & 6.0 \% & 3.12[0.12,78.45]\end{array}$

$1 \quad 48 \quad 20.5 \% \quad 1.95[0.25,15.36]$ 6

$528100.0 \% \quad 1.07[0.41,2.82]$

Test for overall effect $Z=0.15(P=0.88)$

2.1.4 Headached

Brown et. al., 2013

Calvo et. al., 2006

Daniels et. al., 2011

Isola et. al., 2019

Malmstrom et. al., 2004a

Malmstrom et. al., 2004b

Subtotal $(95 \% \mathrm{Cl})$

Total events

$\begin{array}{rr}4 & 283 \\ 0 & 16 \\ 16 & 288 \\ 0 & 32 \\ 2 & 50 \\ 7 & 301 \\ & 970\end{array}$

29

Heterogeneity: $\mathrm{Chi}^{2}=6.92, \mathrm{df}=3(P=0.07) ; I^{2}=57 \%$

Test for overall effect $Z=0.76(P=0.45)$

2.1.5 Alveolar osteitis

Brown et. al., 2013

Calvo et. al., 2006

Daniels et. al., 2011

Isola et. al., 2019

Malmstrom et. al., 2004a

Malmstrom et. al., 2004b

Subtotal $(95 \% \mathrm{Cl})$

Total events

$\begin{array}{rr}0 & 283 \\ 0 & 16 \\ 11 & 288 \\ 0 & 32 \\ 4 & 50 \\ 50 & 301 \\ & 970\end{array}$

65

$63) ; I^{2}=0 \%$

Test for overall effect $Z=0.10(P=0.92)$

Test for subgroup differences: $\mathrm{Chi}^{2}=1.17, \mathrm{df}=4(P=0.88) ; I^{2}=0 \%$

Risk of bias legend

(A) random sequence generation (selection bias)

(B) allocation concealment (selection bias)

(C) blinding of participants and personnel (performance bias)

(D) blinding of outcome assessment (detection bias)

(E) incomplete outcome data (attrition bias)

(F) selective reporting (reporting bias)

(G) other bias
Odds ratio Risk of bias

M-H, fixed, $95 \% \mathrm{Cl}$ A B C D E F G

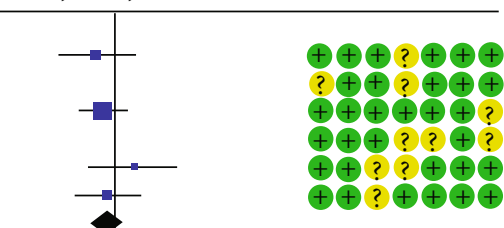

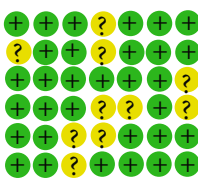

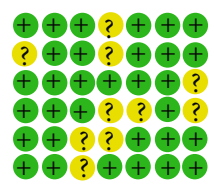
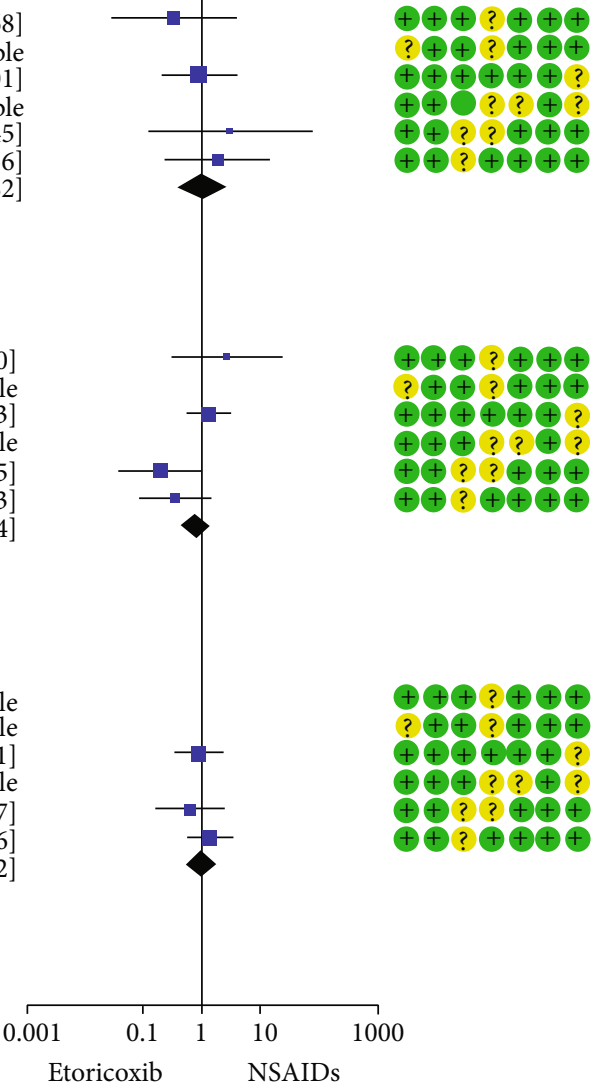


\section{Data Availability}

All data are available in the articles included in our manuscript. If you have any further questions feel free to contact me.

\section{Conflicts of Interest}

The authors have no conflicts of interest to declare.

\section{Supplementary Materials}

Table S1: characterization of the high-quality studies. (Supplementary Materials)

\section{References}

[1] S. Hellem, G. Persson, N. Freiberg, P. G. Nord, B. Gustafsson, and B. Huitfeldt, "A model for evaluating the analgesic effect of a new fixed ratio combination analgesic in patients undergoing oral surgery," International Journal of Oral Surgery, vol. 8, no. 6, pp. 435-442, 1979.

[2] R. A. Seymour and J. G. Walton, "Pain control after third molar surgery," International Journal of Oral Surgery, vol. 13, no. 6, pp. 457-485, 1984.

[3] L. Szmyd, I. L. Shannon, and A. M. Mohnac, "Control of postoperative sequelae in impacted third molar surgery," Journal of Oral Therapeutics and Pharmacology, vol. 1, pp. 491-496, 1965.

[4] R. A. Seymour, J. G. Meechan, and G. S. Blair, "An investigation into post-operative pain after third molar surgery under local analgesia," British Journal of Oral and Maxillofacial Surgery, vol. 23, no. 6, pp. 410-418, 1985.

[5] E. Urquhart, "Analgesic agents and strategies in the dental pain model," Journal of Dentistry, vol. 22, no. 6, pp. 336-341, 1994.

[6] J. G. Meechan and R. A. Seymour, "The use of third molar surgery in clinical pharmacology," British Journal of Oral Maxillofacial Surgery, vol. 31, no. 6, pp. 360-365, 1993.

[7] J. Barden, J. E. Edwards, H. J. McQuay, P. J. Wiffen, and R. A. Moore, "Relative efficacy of oral analgesics after third molar extraction," British Dental Journal, vol. 197, no. 7, pp. 407411, 2004.

[8] A. T. Çebi, M. B. Kasapoğlu, S. Eren, and Ç. Kasapoğlu, "Comparison of the effects of diclofenac potassium and tenoxicam on postoperative pain, swelling, and trismus following third molar surgery," Turkish Journal of Medical Sciences, vol. 48, no. 2, pp. 271-278, 2018.

[9] G. G. Song, Y. H. Seo, J. H. Kim, S. J. Choi, J. D. Ji, and Y. H. Lee, "Relative efficacy and tolerability of etoricoxib, celecoxib, and naproxen in the treatment of osteoarthritis," Zeitschrift für Rheumatologie, vol. 75, no. 5, pp. 508-516, 2016.

[10] A. González-Barnadas, O. Camps-Font, P. Martín-Fatás, C. Gay-Escoda, E. Valmaseda-Castellón, and E. ValmasedaCastellón, "Efficacy and safety of selective COX-2 inhibitors for pain management after third molar removal: a metaanalysis of randomized clinical trials," Clinical Oral Investigation, vol. 24, no. 1, pp. 79-96, 2020.

[11] S. D. Solomon, J. J. McMurray, M. A. Pfeffer et al., "Cardiovascular risk associated with celecoxib in a clinical trial for colorectal adenoma prevention," The New England Journal of Medicine, vol. 352, no. 11, pp. 1071-1080, 2005.
[12] F. Krötz, T. M. Schiele, V. Klauss, and H. Y. Sohn, "Selective COX-2 inhibitors and risk of myocardial infarction," Journal of Vascular Research, vol. 42, no. 4, pp. 312-324, 2005.

[13] G. Singh, O. Wu, P. Langhorne, and R. Madhok, "Risk of acute myocardial infarction with nonselective non-steroidal antiinflammatory drugs: a meta-analysis," Arthritis Research and Therapy, vol. 8, no. 5, p. R153, 2006.

[14] J. P. Lafrance and D. R. Miller, "Selective and non-selective non-steroidal anti-inflammatory drugs and the risk of acute kidney injury," Pharmacoepidemiology and Drug Safety, vol. 18, no. 10, pp. 923-931, 2009.

[15] P. Sriuttha, B. Sirichanchuen, and U. Permsuwan, "Hepatotoxicity of nonsteroidal anti-inflammatory drugs: a systematic review of randomized controlled trials," International Journal of Hepatology, vol. 2018, Article ID 5253623, 13 pages, 2018.

[16] W. Y. W. Yeung and H. S. Park, "Update on the management of nonsteroidal anti-inflammatory drug hypersensitivity," Yonsei Medical Journal, vol. 61, no. 1, pp. 4-14, 2020.

[17] A. F. M. Albuquerque, C. S. R. Fonteles, D. R. do Val et al., "Effect of pre-emptive analgesia on clinical parameters and tissue levels of TNF- $\alpha$ and IL- $1 \beta$ in third molar surgery: a tripleblind, randomized, placebo- controlled study," International Journal of Oral and Maxillofacial Surgery, vol. 46, no. 12, pp. 1615-1625, 2017.

[18] A. Medeiros-Albuquerque, C. S. Roriz-Fonteles, J. J. do Nascimento-Costa et al., "RT-qPCR study of COX-1 and -2 genes in oral surgical model comparing single-dose preemptive ibuprofen and etoricoxib: a randomized clinical trialy," Journal of Clinincal and Experimental Dentistry, vol. 12, pp. e371-e380, 2020.

[19] J. D. Brown, S. E. Daniels, D. P. Bandy et al., "Evaluation of multiday analgesia with etoricoxib in a double-blind, randomized controlled trial using the postoperative third-molar extraction dental pain model," Clinical Journal of Pain, vol. 29, no. 6, pp. 492-498, 2013.

[20] A. M. Calvo, V. T. Sakai, K. C. S. Modena et al., "Comparison of the efficacy of etoricoxib and ibuprofen in pain and trismus control after lower third molar removal," Revista de Odontología da Universidade Cidade de Sao Paolo, vol. 18, pp. 29-36, 2006.

[21] S. E. Daniels, D. P. Bandy, S. E. Christensen et al., "Evaluation of the dose range of etoricoxib in an acute pain setting using the postoperative dental pain model," Clinical Journal of Pain, vol. 27 , no. 1 , pp. 1-8, 2011.

[22] G. Isola, G. Matarese, A. Alibrandi et al., "Comparison of effectiveness of etoricoxib and diclofenac on pain and perioperative sequelae after surgical avulsion of mandibular third molars," Clinical Trial Clinical Journal of Pain, vol. 35, no. 11, pp. 908-915, 2019.

[23] K. Malmstrom, P. Kotey, H. Coughlin, and P. J. Desjardins, “A randomized, double-blind, parallel-group study comparing the analgesic effect of etoricoxib to placebo, naproxen sodium, and acetaminophen with codeine using the dental impaction pain model," Clinical Journal of Pain, vol. 20, no. 3, pp. 147155, 2004.

[24] K. Malmstrom, A. Sapre, H. Couglin, N. G. B. Agrawal, R. S. Mazenko, and J. R. Fricke Jr., "Etoricoxib in acute pain associated with dental surgery: a randomized, double-blind, placeboand active comparator-controlled dose-ranging study," Clinical Therapeutics, vol. 26, no. 5, pp. 667-679, 2004.

[25] R. Leonardo, "PICO: model for clinical questions," Evidence Based Medicine and Practice, vol. 3, no. 115, p. 2, 2018. 
[26] P. P. Higgins and S. Green, Cochrane handbook for systematic reviews of interventions version 5.1.0 [updated March 2011], The Cochrane Collaboration, Oxford, 2011, http://www .cochrane-handbook.org/.

[27] A. Jones and D. Steel, "Evaluating the quality of medical evidence in real-world contexts," Journal of Evaluation in Clinical Practice, vol. 24, no. 5, pp. 950-956, 2018.

[28] The GRADE Working Group, D. Atkins, M. Eccles et al., "Systems for grading the quality of evidence and the strength of recommendations I: critical appraisal of existing approaches the GRADE working group," BMC Health Services Research, vol. 4, no. 1, p. 38, 2004.

[29] G. H. Guyatt, A. D. Oxman, G. E. Vist et al., "GRADE: an emerging consensus on rating quality of evidence and strength of recommendations," British Medical Journal, vol. 336, no. 7650, pp. 924-926, 2008.

[30] T. M. Huynh, E. Marret, and F. Bonnet, "Combination of dexamethasone and local anaesthetic solution in peripheral nerve blocks: a meta-analysis of randomised controlled trials," European Journal of Anaesthesiology, vol. 32, no. 11, pp. 751758, 2015.

[31] E. Whitley and J. Ball, "Statistics review 3: hypothesis testing and P values," Critical Care, vol. 6, no. 3, pp. 222-225, 2002.

[32] J. P. Higgins, S. G. Thompson, J. J. Deeks, and D. G. Altman, "Measuring inconsistency in meta-analyses," British Medical Journal, vol. 327, no. 7414, pp. 557-560, 2003.

[33] Z. S. Madani, A. A. Moghadamnia, A. Panahi, and A. Poorsattar Bejeh Mir, "Analgesic effect of etoricoxib compared to ibuprofen on post endodontic pain," Oral Health and Dental Management, vol. 12, no. 3, pp. 186-190, 2013.

[34] J. Girano-Castaños, C. Peña-Soto, and J. Girano-Castaños, "Efecto analgésico del etoricoxib y el ketorolaco vía oral en cirugía periodontal," Asociación Peruana de Periodoncia y Oseointegración, vol. 1, pp. 1-5, 2016.

[35] K. Konuganti, M. Rangaraj, and A. Elizabeth, "Pre-emptive 8 $\mathrm{mg}$ dexamethasone and $120 \mathrm{mg}$ etoricoxib for pain prevention after periodontal surgery: a randomised controlled clinical trial," Journal of Indian Society of Periodontology, vol. 19, no. 4, pp. 474-476, 2015.

[36] J. P. Steffens, F. A. Santos, R. Sartori, and G. L. Pilatti, "Preemptive dexamethasone and etoricoxib for pain and discomfort prevention after periodontal surgery: a double-masked, crossover, controlled clinical trial," Journal of Periodontology, vol. 81, no. 8, pp. 1153-1160, 2010.

[37] L. N. Zardo, F. A. dos Santos, and G. L. Pilatti, "Use of etoricoxib and dexamethasone for postoperative pain prevention and control in mucogingival surgery: a randomized parallel double-blind clinical trial," Brazilian Journal of Oral Sciences, vol. 12, no. 4, pp. 345-351, 2013.

[38] A. Lisboa and G. L. Pilatti, "Pain control with dexamethasone, etoricoxib or ibuprofen associated with arginine in impacted third molar surgery," Revista Gaúcha de Odontologia, vol. 61, pp. 335-340, 2013.

[39] K. Punnagai, K. Gunasekaran, K. Vijaybabu, and I. G. Josephine, "Efficacy and safety of diclofenac sodium and etoricoxib in controlling post extraction dental pain - a randomized open label comparative study," International Journal of Basic Medical Sciences, vol. 2, pp. 151-157, 2011.

[40] R. I. Chacón-Carrión, A. S. Asmat-Abanto, and R. E. EspejoCarrera, "Analgesic effectiveness of sodium naproxen and etoricoxib post simple dental extraction: parallel randomized clinical trial," International Journal of Odontostomatology, vol. 13, no. 2, pp. 241-246, 2019.

[41] H. McQuay, D. Carroll, and A. Moore, "Variation in the placebo effect in randomised controlled trials of analgesics: all is as blind as it seems," Pain, vol. 64, no. 2, pp. 331-335, 1996.

[42] D. Riendeau, M. D. Percival, C. Brideau et al., "Etoricoxib (MK-0663): preclinical profile and comparison with other agents that selectively inhibit cyclooxygenase-2," The Journal of Pharmacology and Experimental Therapeutics, vol. 296, no. 2, pp. 558-566, 2001.

[43] L. Franco de la-Torre, Á. J. Alonso-Castro, J. R. ZapataMorales et al., "Antinociception and less gastric injury with the dexketoprofen-tapentadol combination in mice," Fundamental and Clinical Pharmacology, vol. 35, no. 2, pp. 371378, 2021.

[44] M. Janovsky and M. Krsiak, "Codeine did not increase analgesic efficacy of coxibs in contrast to that of paracetamol or ibuprofen: isobolographic analysis in mice," Neuro Endocrinology Letters, vol. 32, no. 2, pp. 164-169, 2011.

[45] H. F. Miranda, M. M. Puig, J. C. Prieto, and G. Pinardi, "Synergism between paracetamol and nonsteroidal antiinflammatory drugs in experimental acute pain," Pain, vol. 121, no. 1, pp. 22-28, 2006.

[46] S. Aldington, P. Shirtcliffe, M. Weatherall, and R. Beasley, "Systematic review and meta-analysis of the risk of major cardiovascular events with etoricoxib therapy," New Zeeland Medical Journal, vol. 118, p. U1684, 2005.

[47] The Cochrane Collaboration, R. Clarke, S. Derry, R. A. Moore, and H. J. McQuay, "Single dose oral etoricoxib for acute postoperative pain in adults," Cochrane Database of Systematic Reviews, vol. 2, article CD004309, 2009.

[48] The Cochrane Collaboration, R. Clarke, S. Derry, and R. A. Moore, "Single dose oral etoricoxib for acute postoperative pain in adults," Cochrane Database of Systematic Reviews, vol. 4, article CD004309, 2012.

[49] R. Clarke, S. Derry, R. A. Moore, and Cochrane Pain, Palliative and Supportive Care Group, "Single dose oral etoricoxib for acute postoperative pain in adults," Cochrane Database of Systematic Reviews, vol. 5, article CD004309, 2014.

[50] H. S. Baraf, C. Fuentealba, M. Greenwald et al., "Gastrointestinal side effects of etoricoxib in patients with osteoarthritis: results of the Etoricoxib versus Diclofenac Sodium Gastrointestinal Tolerability and Effectiveness (EDGE) trial," Journal of Rheumatology, vol. 34, pp. 408-420, 2007.

[51] R. de Vecchis, C. Baldi, G. di Biase et al., "Cardiovascular risk associated with celecoxib or etoricoxib: a meta-analysis of randomized controlled trials which adopted comparison with placebo or naproxen," Minerva Cardioangiologica, vol. 62, no. 6, pp. 437-448, 2014.

[52] J. Zhang, E. L. Ding, and Y. Song, "Adverse effects of cyclooxygenase 2 inhibitors on renal and arrhythmia events: metaanalysis of randomized trials," JAMA, vol. 296, no. 13, pp. 1619-1632, 2006.

[53] N. Panic, E. Leoncini, G. de Belvis, W. Ricciardi, and S. Boccia, "Evaluation of the endorsement of the preferred reporting items for systematic reviews and meta-analysis (PRISMA) statement on the quality of published systematic review and meta-analyses," PLoS One, vol. 8, no. 12, article e83138, 2013.

[54] G. Urrútia and X. Bonfill, "PRISMA declaration: A proposal to improve the publication of systematic reviews and meta- 
analyses," Medicina Clinica (Barc), vol. 135, no. 11, pp. 507$511,2010$.

[55] J. M. Argimon-Pallás and J. Jiménez-Villa, Métodos de investigación clínica y epidemiológica, Elsevier. Barcelona, España, 5th ed. edition, 2019.

[56] B. Dawson and R. G. Trapp, Bioestadística médica, Editorial El Manual Moderno, México, D.F, 4th ed. edition, 2005. 